\title{
A Study Of Faculty Job Satisfaction And Its Impact On Student Satisfaction In Management Institutes Of Nashik District Affiliated To University Of Pune.
}

\author{
Bhavna R Shetty ${ }^{1}$, Dr. Rajashree Gujarathi ${ }^{2}$ \\ ${ }^{1}$ (Lecturer, Shri SPK \& Smt GSK Institute of Computer Science \& Technology Management, Nashik, India.) \\ ${ }_{2}^{2}$ (Professor, Sinhgad Institute of Business Management, Mumbai, India).
}

\begin{abstract}
Most of the higher educational institutes throughout the country are suffering from acute shortage of faculty. The effect of high faculty attrition is borne by students for no fault of theirs. Teaching has also become an unattractive profession today for which young talents prefer other hefty paid salaried jobs and career options. Thus objective of this research paper is two folded; firstly to identify factors of faculty job satisfaction and student's overall satisfaction in this knowledge economy, and secondly to examine the role of faculty job satisfaction in generating student satisfaction. Chi square test was used to test the hypotheses; to determine the association of faculty's job satisfaction level with faculty's salary and also with students' overall satisfaction level. Results indicate that in today's fast changing economy, faculty members thrive for professional growth and development, not just salary; to secure better positions in future. The findings of this research paper also propagate the concept of Human Sigma within educational context, stating that a contended faculty is a source of students' satisfaction, but for this faculties need to be retained and satisfied.
\end{abstract}

Keywords: faculty job satisfaction, faculty retention, human sigma, management institutes, student satisfaction.

\section{Introduction}

Today more than ever before in human history, the wealth or poverty of a nation depends on the quality of the higher education (Malcolm Gillis, 1999). India has one of the largest Higher Education (HE) systems in the world. There are three principle levels of qualifications within the degree structure of Indian HE system; the bachelor/undergraduate level, master's/post-graduate level and doctoral/pre-doctoral level; also included are diploma courses at undergraduate and post graduate level. Management institutes a part of higher education system, determine the career paths of the youth and in turn the future of the country. Students, parents, teachers, staff and society in general are the stakeholders of these institutes. Faculty members, the core eighty percent human resource of any management institute, have the potential and power to transform the future generation of our country.

The most important information to have regarding an employee in an organization is a validated measure of his/her level of job satisfaction (Roznowski and Hulin 1992). Behavioural and social science research suggests that job satisfaction and job performance are positively correlated (Bowran and Todd 1999). A better understanding of job satisfaction and factors associated with it is helpful to guide employees' activities in a desired direction. Job satisfaction, for example, is significantly linked to factors like employee motivation and performance (Ostroff, 1992), employee absenteeism (Hackett \& Guion, 1985) and turnover (Griffeth, Horn, \& Gaertner, 2000) and even positively influences organizational citizenship behavior (Organ \& Ryan, 1995). Satisfaction is a relevant measure because many studies have demonstrated that other factors being equal, satisfied individuals are likely to be willing to exert more effort than unsatisfied individuals (Bryant, 2006; Özgüngör, 2010). The same holds true for satisfied faculty members and students as well in education institutes. The importance of this research paper is two folded; firstly to identify factors of faculty job satisfaction and student's overall satisfaction in this knowledge economy, and secondly examines the role of faculty job satisfaction in generating student satisfaction.

As employee turnover continues to be a serious business predicament, the concept of job satisfaction assumes significance not only for contemporary business scenario but also for educational sectors that are facing acute shortage of qualified and competitive teaching work force. Faculty job satisfaction levels seem to have direct bearing on the institutional as well as the student development and an understanding of job satisfaction, retention and employee turnover aspects of the faculties would help policy makers understand a very important organ of the society, responsible for future of the nation and generation.

According to the Department of Higher Education, Ministry of Human Resource Development MHRD, educational sector has witnessed a tremendous increase in its institutional capacity since independence. Over the years, the number of management institutes for higher learning has increased tremendously; but this growth in number of institutes and enrollment of students has not been supported by proportionate growth in number of 
faculties. Most of the higher educational institutes throughout the country are suffering from acute shortage of faculty, not to mention good faculty members. To face faculty crisis, educational institutes opt for ad hoc, part time or visiting faculties who teach only for a few couple of hours. These faculties are least committed towards the institute; as they work in multiple places to make a living. They are thus frustrated and not motivated. Ironically, the effect of high faculty attrition is borne by the students for no fault of theirs. There is need to identify the issues associated with faculty job satisfaction and retention and pave out proper solutions for the same. In an attempt to increase the Gross Enrolment Ratio (GER) in higher education to $21 \%$ by the end of the $12^{\text {th }}$ five year plan period from the current $13.5 \%$, MHRD has formulated an action plan to achieve this target. Raising the GER would entail an additional enrollment of over 26 million in higher education and almost one million school teachers by 2020. For faculty attraction and retention, the ministry is mulling Human Resource Planning and Management (HRPM) centers at the university level to assess teacher requirement and plan their professional growth research and faculty development programmes such as seminars, training, workshops, incentives and award schemes. It is being suggested that a concerted strategy to retain best talents in universities for faculty positions and preparing secondary teachers be formulated.

The most important product of educational institutions is a qualified and satisfied student; the second concept under study in the research. Students' satisfaction surveys are important in ascertaining whether colleges and universities are fulfilling their mission. Satisfied students are more likely to be committed and continue their studies (as measured by a higher retention rate) than unsatisfied students, who are likely to be less willing to regularly attend classes, and are more likely to quit their studies (Jamelske, 2009; Borden, 1995). Institutes have assessed students' satisfaction for many reasons. Some have measured the levels of student satisfaction in order to examine accountability reporting and self-improvement process across departments and colleges; others have examined student satisfaction to determine if satisfaction ratings of college programs and services are associated with the satisfaction of the overall college experience. Still others have investigated student satisfaction items related to issues such as student retention and attrition.

\subsection{Significance of the study}

Most of the research on job satisfaction is related to industrial or business organization; and even if faculty job satisfaction has been studied earlier, unfortunately not much attention is drawn towards studying the influence of having satisfied faculty upon student satisfaction level in education institutes. The following key benefits highlight the significance of this research effort:

1. Deal with faculty shortage: In order to survive, management institutes have to face several challenges and faculty crisis is perhaps the most critical. The current and predicted shortages of competent faculty members can go from 'concern' to 'crises' in coming decades. Faculty job satisfaction can improve faculty retention rate and arrest attrition rate.

2. Sustain Quality of education: Quality faculty is must for quality education. Quality is not inborn, it needs to be inculcated \& practiced, which in turn calls for continuous training and commitment on part of the faculty members. A satisfied faculty will take initiative and keen interest towards training programs in true sense.

3. Student satisfaction: Faculty members working for the cause of higher education need to be retained with the view to providing top class education and satisfaction to the students..

4. Organizational commitment: Better job satisfaction will provide current faculty members a reason to continue with the institute and stay committed.

5. Image building of the institute: Satisfaction and retention of qualified faculty is an important factor in maintaining the identity and professional climate of a management institute and to improve its reputation in the market.

6. Attract fresh talent towards teaching profession: Teaching has become an unattractive profession today for which young talents prefer other hefty paid salaried jobs and career options. Faculty retention strategies can improve the image of teaching as a profession and thereby make it an attractive career option for the youth of the country.

Nashik is deemed "the third most industrialized city of Maharashtra after Mumbai and Pune", mainly due to extensive industrial development in recent times. Today, Nashik is rated as one of India's fastest growing cities. The city is gaining preference as an educational hub, becoming students' alternative option to technical and management education; next to Pune. Thus the number of management institutes recognized by Pune University in Nashik district today has gone upto to 36. Despite of increased job opportunities in management institutes, faculty shortage remains central issue. Hence Nashik district was chosen as the study area for this research work.

Keeping in view all the above mentioned factual and doubtful factors associated with the study, a detailed study of various factors of faculty job satisfaction and specifically its impact on students' satisfaction level deserves a strong rationalization. The findings of the study will be of enormous use to the management as well as faculty of management institutes, in general. The report of this study may be useful for management 
institutes to develop work environment and culture that would allow higher levels of faculty job satisfaction and retention to enhance overall student satisfaction. On other hand, faculty members will become more aware of their expectations from the job. It will foster a better understanding between the management and faculty members so as to achieve institutional objectives in the long run.

\section{Literature Review}

Three theoretical frameworks of job satisfaction can be identified in the literature (Green 2000). Framework one is based on content theories of job satisfaction. Content theorists assume that fulfillment of needs and attainment of values can lead to job satisfaction (Locke, 1976). Framework two is grounded in process theories of job satisfaction. Process theorists assume that job satisfaction can be explained by investigating the interaction of variables such as expectancies, values, and needs (Gruneberg, 1979). Framework three is rooted in situational models of job satisfaction (Thompson \& McNamara, 1997). Situational theorists assume that the interaction of variables such as task characteristics, organizational characteristics, and individual characteristics influences job satisfaction (Hoy \& Miskel, 1996). Locke and Lathan's (1976) defined job satisfaction as a "pleasurable or positive emotional state resulting from the appraisal of one's job or job experience. Many experts believe that job satisfaction is not only an indicator of overall individual well-being (Diaz-Serrano and Cabral Vieira, 2005), but also a good predictor of intentions or decisions of employees to leave a job (Gazioglu and Tansel, 2002).

Teacher job satisfaction is often cited and rendered important in both research on teacher attrition and teacher retention (Roach, 1991; Voke, 2002; Stockard \& Lehman, 2004). Researchers and scholars have tried to understand the high teacher turnover rate among beginning teachers by investigating the reasons and causes behind both teacher retention and teacher attrition (Connolly, 2000; Ingersoll, 2003; Ingersoll \& Smith, 2003; Howard, 2003; Inman \& Marlow, 2004; Heller, 2004; Stockard \& Lehman, 2004). It must be taken into account that the source of job satisfaction is not always salary; but also the job content and context, that generates from working environment, management style, interpersonal relationship and organizational culture. Non-salary incentives like early promotion, research allowances, more frequent leaves of absence, and reduced teaching loads (Bowen \& Sosa, 1989) can also help recruit and retain faculty without raising salaries. Hughes (1991) in his research found professional growth as fundamental motivators and component of teachers career development that gives them effectiveness and satisfaction in teaching. Teacher job satisfaction is frequently associated with burnout, work quality and professionality. A study by Gill (1992) reported that six of the top seven reasons for faculty departing were intangible benefits such as research opportunities; higher compensation levels increased the retention of assistant and associate professors, but had no effect on retaining professors. For the purpose of understanding how higher education institutions can retain women faculty members, Wenzel and Hollenshead (1994) studied attitudes of tenured women faculty and identified blocked career opportunities, receiving disrespectful treatment, insufficient personal or financial support, mismatched personal and institutional goals as negative aspects of the university work environment that influenced faculty attrition. Likewise, Lynn (2002) supported the idea that educational leaders should provide professional learning and growth opportunities in order to motivate teachers and to enhance their performance.

The Emerging Directions in Global Education (EDGE) survey report 2009, on 'Faculty Recruitment and Retention-The Issues and Challenges' throws light on the challenges involving faculty recruitment and retention in India. The survey reports that average attrition rate in academic institute was about 25 percent per annum. Compensation along with other employee benefits were the two major professional reasons for the faculty to leave the institute, whereas job security is another additional factor in case of private institutes. Factors like family living locally and availability of school in the locality are given more importance by the private institute faculties. According to students' view 60 per cent of the faculty exit during the academic year which badly affects their studies. This trend was much higher in case of private institutes as compared to their government counterpart. Students also opined that availability of better compensation and career option and lack of growth opportunities in the existing institutes resulted in faculty exit. Strategies suggested by the report for faculty retention were promotion based on performance, faculty freedom, encouraging research programme, training, opportunities for career growth, transparent appraisal system and housing facility. The report finally concludes that introducing innovative HR tools in line with the corporate sectors may help in bringing down the attrition rate to some extent.

College students' satisfaction has been conceptualized by researchers in various ways as "satisfaction with college experience" (Elliott \& Healy, 2001; Peters, 1988; Billups, 2008), "satisfaction with quality of instruction" (Aman, 2009), "satisfaction with advising" (Corts, Lounsbury, Saudargas, Tatum, 2000; Elliott, 2003; Olson, 2008; Peterson, Wagner, and Lamb, 2001), "satisfaction with assessment" (Kane, 2005; Ross, Batzer, \& Bennington, 2002), "satisfaction campus-wide" (Benjamin \& Hollings, 1997), and "satisfaction with an academic department" (Corts et al., 2000). Quality in higher education means enabling students to achieve learning goals and academic standards in effective educational environment (Venkatraman, 2007). Research has proved that faculty has a major impact on students' learning (Hill, et al, 2003) and is the main strength in an 
educational institution (Gary, 2005). Quality in teaching and learning can only be enhanced if the faculty members are satisfied and content (Chen, 2006). In order to make students understand the value of their education and make them satisfied with their overall experience, satisfied faculty members are needed. A study by Peng and Samah (2006) that attempted to discover factors of education service contributing the most to students' satisfaction level, identified lecturer and faculty as significant affecting factor. Faculty will be effective and competent in achieving the desired learning outcomes, provided they are satisfied with their profession. When students are satisfied with their faculty and institute; they are likely to become more involved with their studies and give better results.

\section{Objectives Of The Study}

The primary research objective of this study was to provide more practical data on the job satisfaction levels of faculty and its influence on students' overall satisfaction level.

1. To establish the importance of having satisfied faculty members and its role in overall students' satisfaction level.

2. To identify and understand various factors affecting faculty job satisfaction, retention and attrition in management institutes.

3. To identify factors affecting students' performance and satisfaction level in management institutes.

4. To suggest appropriate measures to improve the faculty satisfaction rate of management institutes, through the final study report.

\section{Hypotheses For The Study}

Hypothesis H1: In management institutes faculty job satisfaction is positively associated to faculty's salary.

Job satisfaction is a result of employee's perception of how well their job provides those things that are viewed as important. Hypothesis $\mathrm{H} 1$ is based on assumption that if faculty positions become less economically attractive, the level of dissatisfaction could rise substantially. As faculty compare their salaries not only to those in other professions, but also to other faculties, inside and outside of their institutions; salary becomes an important determinant of job satisfaction.

\section{Hypothesis H2: In management institutes high level of faculty job satisfaction is positively associated with} high level of students' satisfaction level.

The assertion made in this paper is that there exists a relation between faculty job satisfaction and student satisfaction; that influences student performance, learning and motivation. If faculty members stay dissatisfied and disinterested with their jobs, it is apparently going to have direct consequences on students. To grasp the complexity of students' satisfaction, it is not enough to know only the degree to which students are satisfied, but to understand the factors that contribute to their satisfaction. Most scholars agree that the relationships between students and faculty are vital to student success in college (Kuh, Kinzie, Schuh, Whitt, \& Associates, 2005). In this study, student satisfaction is conceptualized as "overall satisfaction with faculty and institute related factors".

A score of seventy percent and more on respective satisfaction scales was considered as high level of satisfaction for the purpose of this study.

The conceptual framework proposed for this research study is shown in fig 1 .

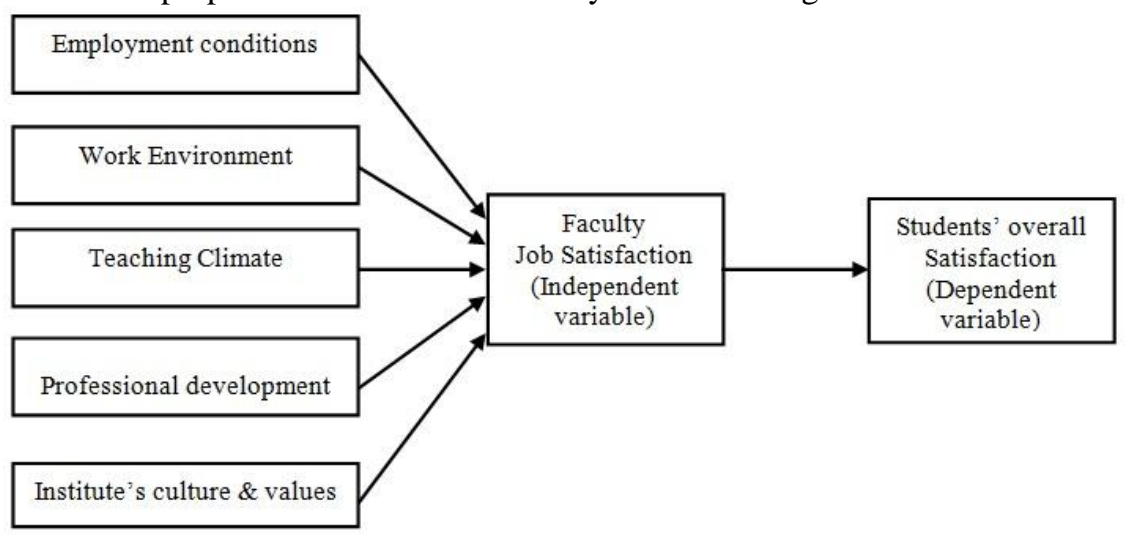

Figure 1: Conceptual framework of faculty job satisfaction and student satisfaction. 


\section{Research Methodology}

5.1 Survey instrument: The primary data for this study was collected from two important sources of management institutes; the faculty members and students. Non probability convenience sampling technique was adopted. Two separate self completion questionnaires were designed, based on earlier studies; one for faculty members and the other for students. A pilot study was carried out to test the reliability of the self developed scales and as the scales showed high reliability they were considered as good measures for main phase study.

5.2 Independent variable: The independent variable 'faculty job satisfaction' was measured on five factors employment conditions $(\alpha=0.81)$, work environment $(\alpha=0.77)$, teaching climate $(\alpha=0.80)$, professional development $(\alpha=0.79)$ and institute's culture and value $(\alpha=0.74)$; in all covering 28 items. Five-point Likert rating scale was used with ' 5 ' indicating 'highly satisfied' and ' 1 ' indicating 'highly dissatisfied' conditions. For the purpose of this study a score equal to or more than seventy percent was considered as high job satisfaction. Faculties were also asked to rank order six factors important from their retention and attrition point of view.

5.3 Dependent variable: Students' overall satisfaction, the dependent variable was measured on two factors using a self designed scale. First factor related to faculty $(\alpha=0.78)$, with items like faculty's concern for students, competent and knowledgeable faculty, quality of interaction between faculty and students, faculty's expectations from students and so on. The second factor of satisfaction related to institute $(\alpha=0.76)$, campus interviews, availability of academic advisors or counselors, amount of financial aid/scholarships available, additional training in form of workshops \& seminars, reputation of the institute. To test hypothesis H2, students were asked to rank following factors 'self interest and competency', 'faculty leaving during an academic year', 'faculty retention throughout the completion of course', 'facilities provided by institute' and 'family support' in order of its impact on their performance and satisfaction level. To understand faculty members' perception about factors influencing students' performance and satisfaction, they were also asked to rank order above five factors.

\section{Results And Findings}

The survey was conducted in management institutes of Nashik district affiliated to University of Pune; profile of the respondents included working professors, assistant professors, lecturers and students.

\subsection{Findings related to faculty members:}

- Out of the 100 questionnaires distributed; 48 faculty members responded (48\% response rate) by returning completely filled questionnaires. Demographics of the respondents showed that $63 \%$ were female faculties. $76 \%$ of the respondents represented young faculty belonging to $26-35$ years age group. Their level of experience showed that $42 \%$ had teaching experience of less than 1 to 2 years and only $2 \%$ had served more than 15 years. A high $58 \%$ of faculties were working on contract basis. $65 \%$ of faculty members were found pursuing a $\mathrm{PhD}$ degree; probable reason being e that achieving a $\mathrm{PhD}$ degree is now linked with promotion by University Grants Commission (UGC) of India.

- A substantial 78\% of faculty members were dissatisfied with their jobs. High level of dissatisfaction was exhibited for professional development $(\mathrm{M}=2.33)$ and employment conditions $(\mathrm{M}=2.47)$, see Table 3. The major issues of concern were time provided for research work, availability of research support \& facilities and promotion policy. Respondents opined that they can't carry out research activities with full efficiency in presence of high workload and non teaching activities. Faculty members when asked to rank factors that had significant impact on their intention to leave current position, the leading ones were 'no future growth', 'job security' and 'lack of support \& freedom' (see Table 1).

- Faculty members were found somewhat satisfied with 'teaching climate' $(M=3.76)$, see Table 3, while respondents were contended with quality of students, availability of teaching aids, reputation \& progress of the institute; they were not much satisfied with participation in decision making and freedom to choose subjects to be taught. Empowerment and recognition proves to be key motivators for job satisfaction. On exploring faculty retention factors, results identified 'career advancement \& promotion' (rank 1) as the foremost important factor, followed by 'salary and leave benefits' (rank 2$)$ and then 'co-operation \& support' (see Table 2). 
A Study of Faculty Job satisfaction and its impact on Student Satisfaction in Management Institutes

Table 1: Ranking of Attrition factors by Faculty
\begin{tabular}{|c|l||}
\hline RANK & ATTRITION Factors \\
\hline \hline 1 & No future growth \\
\hline 2 & Job security \\
\hline 3 & $\begin{array}{l}\text { Lack of support \& freedom by the } \\
\text { director }\end{array}$ \\
\hline 4 & Low Salary \\
\hline 5 & $\begin{array}{l}\text { Isolation/ Poor relationship with } \\
\text { colleagues }\end{array}$ \\
\hline 6 & Personal/ Family reasons \\
\hline
\end{tabular}

Table 2: Ranking of Retention factors by Faculty
\begin{tabular}{|c|l||}
\hline RANK & RETENTION Factors \\
\hline \hline 1 & Promotion \& career advancement \\
\hline 2 & Salary and leave benefits \\
\hline 3 & $\begin{array}{l}\text { Co-operation \& Support from higher } \\
\text { levels }\end{array}$ \\
\hline 4 & Working conditions \\
\hline 5 & $\begin{array}{l}\text { Good relations \& communication } \\
\text { with colleagues }\end{array}$ \\
\hline 6 & Family support \\
\hline
\end{tabular}

It seemed faulty members were hesitant to give their opinion about the work environment $(\mathrm{M}=3.07)$, refer Table 3, and chose to remain neutral for matters like support from colleagues or seniors, relationship with HODs/director and infrastructure. As main concern of most faculties was completing their PhD; less guidance or support in this regard can lead to more job dissatisfaction. Above mentioned findings clearly indicate that faculty members feel strong need of professional development culture, which is an important contributor in their retention and job satisfaction.

Table 3: Mean Scores of factors affecting Faculty Job Satisfaction

\begin{tabular}{|l|c|c|c|}
\hline Factors & N & Mean (M) & SD \\
\hline \hline Employment conditions & 48 & 2.47 & 0.98 \\
\hline Work Environment & 48 & 3.07 & 1.02 \\
\hline Teaching Climate & 48 & 3.76 & 1.23 \\
\hline Professional development & 48 & 2.33 & 0.94 \\
\hline Institute's culture \& values & 48 & 3.24 & 1.15 \\
\hline
\end{tabular}

\subsection{Findings related to students:}

250 questionnaires were distributed to students of which 147 students responded (59\% response rate). $61 \%$ students were pursuing MBA course while the rest had taken up MMM, MPM and MCM courses.

- $64 \%$ students showed high levels of dissatisfaction with faculty related factors, consistency of instructional quality, faculty's concern for students and faculty retention. However students $(73 \%)$ seemed somewhat satisfied or at least neutral with other institute related factors like additional training in form of workshops \& seminars, extra and co-curricular activities, infrastructure and reputation of the institute.

- When we observe ranking of factors influencing students' performance and satisfaction (refer Table 4); it appears that faculty and students share only one factor 'family support' out of five. While students attach great importance to faculty attrition, faculty members seem to have underestimated its impact on students. Striking is the difference in importance attached to the factor 'faculty retention throughout the completion of course'. Faculty members appear to view it differently, ranking it fourth against students ranking it as the top most factor influencing their overall satisfaction level. According to students when it comes to their performance and results, 'faculty leaving during an academic year' is more significant than their own interest and competency. However, same issue is being viewed differently by faculty, as they consider students' interest and competency responsible for students' performance. On the whole there appears to be remarkable difference in the perceptions of faculty members and students regarding factors influencing students' performance and satisfaction.

Table 4: Comparison between student ranking and faculty ranking.

\begin{tabular}{|l|c|c|c|c||}
\hline \hline \multirow{2}{*}{ Influencing Factors } & \multicolumn{2}{|c|}{$\begin{array}{c}\text { Effect on Students' } \\
\text { performance }\end{array}$} & \multicolumn{2}{c|}{$\begin{array}{c}\text { Effect on Students' } \\
\text { overall satisfaction }\end{array}$} \\
\cline { 2 - 5 } & $\begin{array}{c}\text { Ranking } \\
\text { by student }\end{array}$ & $\begin{array}{c}\text { Ranking } \\
\text { by faculty }\end{array}$ & $\begin{array}{c}\text { Ranking } \\
\text { by student }\end{array}$ & $\begin{array}{c}\text { Ranking } \\
\text { by faculty }\end{array}$ \\
\hline Student's self interest and competency & 2 & 1 & 4 & 2 \\
\hline Faculty leaving during an academic year & 1 & 3 & 2 & 3 \\
\hline $\begin{array}{l}\text { Faculty retention throughout the completion } \\
\text { of course }\end{array}$ & 3 & 4 & 1 & 4 \\
\hline Facilities provided by institute & 4 & 2 & 3 & 1 \\
\hline Family support & 5 & 5 & 5 & 5 \\
\hline
\end{tabular}




\subsection{Hypothesis testing}

Chi square test was used to test both the hypotheses; to determine the association of faculty's job satisfaction level with faculty's salary and also with students' overall satisfaction level.

Hypothesis 1: In management institutes faculty job satisfaction is positively associated to faculty's salary.

The computed value of chi square $(\chi 2)$ at degree of freedom (df) equal to one and $5 \%$ significance level was 0.82 . This value being much lesser than the table value 3.841, null hypothesis was accepted; indicating no positive association between faculty job satisfaction and faculty's salary.

Hypothesis 2: In management institutes high level of faculty job satisfaction is positively associated with high level of students' satisfaction level.

For hypothesis $\mathrm{H} 2$ the computed chi square $(\chi 2)$ value 6.00 was greater than the table value 3.841 at degree of freedom (df) ' 1 ' and significance level alpha 0.05 . Hence null hypothesis was rejected. This signifies a positive association of faculty job satisfaction with students' overall satisfaction level.

\section{Conclusions}

It can be concluded that salary is not primary but the secondary determinant of job satisfaction for faculty in today's knowledge economy. This is in agreement with a Fuhrmann (2006) study which stated that although money is an influential factor at every stage but it is not necessary that money alone can increase motivation of every worker. There are intangibles (for instance growth \& development, recognition and feedback) that are primary motivators for the workers inspiration to perform effectively. Salary does not always provide adequate recognition or ensure contentment (Nienhuis, 1994). Some research suggests that perceived equity of pay may be a more important determinant of commitment and satisfaction than basic level of pay (Mowday, 1982). Lack of professional development, time and support provided for research activities were factors responsible for highest dissatisfaction. In this fast changing economy, faculty members today thrive for professional growth and development to secure better positions in future. As most respondents were working on contract basis, the assurance of permanent job and job security could also compensate for lower pay.

The findings of this research paper propagate the theory of 'Human Sigma' as developed by Fleming and Asplund (2007) in educational settings. It proves a strong positive correlation between employee (faculty) satisfaction and customer (students) satisfaction. Employee and customer experiences need to be managed together, not as separate entities. The internal customer satisfaction would always be a precondition to orientation and satisfaction of the external customer (Shaney, Banwet \& Karunes, 2008). The findings also demonstrate difference in views of faculty and students concerning factors influencing students' performance and overall satisfaction. Students perceive both, faculty attrition during academic year as well as during the course as factors hampering their performance or satisfaction. A satisfied faculty is a source of students' satisfaction but for this they need to be retained and satisfied.

7.1 Limitations The major limitation of this study is that it may not be appropriate to generalize its findings, owing to the small sample size and study area being limited only to Nashik district. Also the data obtained through questionnaires were all self-reports from the participants hence the findings may be subject to response consistency effect.

\section{Future Research}

For further research a model which focuses on faculty need for professional growth and research opportunities is proposed; as these can achieve faculty satisfaction. A study on how to retain and attract talented faculty, especially the growing percentage of women faculty in other cities and states of India will be significant. Further research on the relationship between faculty satisfaction and students' satisfaction in educational institutes can be of great importance to attract students in face of growing competition. Despite its limitation this study introduces the concept of Human Sigma in educational context and keeping in mind this concept is really in its infancy in education environment, the scope for future research and developments in this regard is enormous.

\section{References}

[1]. S.M. Abbas, Vandana Premi, Anat Jyoti, Job satisfaction in management faculties of a metropolitan and proximate area: a study on private colleges, International Journal of Research in Commerce and Management, 3(4), 2010, 11-22.

[2]. Radhakanta Gartia and Jagannath Das, 'HE in India: A Reality Check', University News, 47(02), 2009, 12-18.

[3]. S Mohan Karuppayil, Teachers:The neglected Elements of Our Higher Education System, University News, 46(11),2008, 17-23.

[4]. Mussie Tessema, Kathryn Ready, Wei-Choun, Factors Affecting College Students' Satisfaction with Major Curriculum: Evidence from Nine Years of Data, International Journal of Humanities and Social Science, 2(2), 2012, 34-44 
[5]. Muhammad Imran Rasheed, Hassan Danyal Aslam, Shakeel Sarwar (2010), Motivational Issues for Teachers in Higher Education: A Critical Case of IUB, Journal of Management Research, 2(2), 1-23

[6]. Adee Athiyaman,(1997), Linking student satisfaction and service quality perceptions:the case of university education, European Journal of Marketing, 31(7), 528-540.

[7]. Jeffrey Pfeffer and Nancy Langton (1993),The Effect of Wage Dispersion on Satisfaction, Productivity, and Working Collaboratively: Evidence from College and University Faculty, Administrative Science Quarterly, 3(3), 382-407.

[8]. Filak, V. F, Student Psychological Need Satisfaction and College Teacher-Course Evaluations, Educational Psychology, 23(3), 003, 235-247.

[9]. Uzma Quraishi, Ishtiaq Hussain, Makhdoom Ali Syed, Farah Rahman, Faculty Satisfaction In Higher Education: A TQM Approach, Journal of College Teaching \& Learning, 7(6), 2010, 31-34

[10]. Luis Gomez, David Balkin, Faculty satisfaction with pay and other job dimensions under union and nonunion conditions, The Academy of Management Journal, 27(3), 1984, 591-602.

[11]. David E. Terpstra, Andre L. Honoree, Job Satisfaction and Pay Satisfaction Levels of University Faculty by Discipline Type and by Geographic Region, Education, 124(3), 2004, 528-539.

[12]. Jaime X. Castillo, Jamie Cano, Factors Explaining Job Satisfaction Among Faculty, Journal of Agricultural Education, 45(3), 2004, $65-74$.

[13]. Kevin Chung, Jae W JW Song, H Myra HM Kim, James O JO Woolliscroft, Elisabeth H Quint, Nicholas W Lukacs and Margaret R Gyetko, Predictors of job satisfaction among academic faculty members: do instructional and clinical staff differ?, Medical Education, 44(10), 2010, 985-995

[14]. Riaz Mangi, Hassan Soomro, Dr. Ikhtiar Ghumro, Asad Abidi, Dr. Amanat Jalbani (2011), A Study Of Job Satisfaction Among Non Phd Faculty In Universities, Australian Journal of Business and Management Research, 1(7), 83-90.

[15]. Ahsan, Nilufar., Abdullah, Zaini., Fie, David., \& Alam, Syed, A Study Of Job Stress On Job Satisfaction Among University Staff In Malaysia: Empirical Study. European Journal Of Social Sciences, 8(1), 2009, 121-131.

[16]. DeShields Jr.O.W., Kara. A, Kaynak. E, Determinants of Business Student Satisfaction And Retention In Higher Education: Applying Herzberg's Two-Factor Theory, International Journal of Educational Management 19(2), 2005, 128-139.

[17]. Barry Bozeman, Monica Gaughan, Job Satisfaction among University Faculty: Individual, Work, and Institutional Determinants, The Journal of Higher Education, 82 (2), 2011, 154-186.

[18]. Hill, Y., Lomas, L., and MacGregor, J, Students' perceptions of quality in higher education, Quality Assurance in Education,11(1),2003, 15-20.

[19]. Michael Guolla, Assessing the Teaching Quality to Student Satisfaction Relationship: Applied Customer Satisfaction Research in the Classroom, Journal of Marketing Theory and Practice, 7(3), 1999, 87-97.

[20]. Muhammad Ehsan Malik, Samina Nawab, Basharat Naeem, Rizwan Qaiser Danish, Job Satisfaction and Organizational Commitment of University Teachers in Public Sector of Pakistan International Journal of Business and Management, 5(6), 2010, 17-26

[21]. Gary, W., David, S., and Derek, Z, Academic preparation, effort and success: A comparison of student and faculty Perceptions, Educational Research Quarterly, 29(2), 2005, 29-36.

[22]. Khurram Shahzad, Humera Mumtaz, Khansa Hayat, Muhammad Amanullah Khan, Faculty Workload, Compensation Management and Academic Quality in Higher Education of Pakistan: Mediating, European Journal of Economics, Finance and Administrative Sciences, 27, 2010, 112-119

[23]. Paul D. Umbach, Matthew R. Wawrzynski, Faculty Do Matter: The Role of College Faculty in Student Learning and Engagement, Research in Higher Education, 46(2), 2005, 153-184. 